\title{
Ergonomic Assessment of Occupational Health Hazards to Farm Workers in Crop Protection Activities
}

\author{
Rekha Vyas* \\ Professor and Associate Director, Maharana Pratap University of Agriculture and \\ Technology, Udaipur, India \\ *Corresponding Author: Rekha Vyas, Professor and Associate Director, Maharana \\ Pratap University of Agriculture and Technology, Udaipur, India.
}

DOI: 10.31080/ASAG.2020.04.0800
Received: January 28, 2020

Published: February 10, 2020

(C) All rights are reserved by Rekha Vyas.

\begin{abstract}
Crop protection is important to control weeds, pest, insects and diseases in crops as it hinders in yield and quality of produce. But they may cause harm to human health because of their toxic nature and long persistence in the environment where the farmers work. Prolonged exposure may result in chronic diseases. The health hazards in crop protection found were categorized under physiological hazards such as body pain, fatigue, sprains, ligament pull, headache, and fever, mechanical hazards such as injury, cuts and accidents due to spraying equipment, chemical hazards such as skin or respiratory problems due to insecticides, fungicides, pesticides etc. used and environmental hazards due to extreme weather conditions. The main causes elicited for hazards during crop protection activities were duration of exposure, non-use of PPE, improper work methods, personal habits, ignorance of safety instructions and unsafe storage and handling of chemicals. Thus, it is important that the farmers must be made aware about the hazards through proper training and educational interventions. Then only, the health of half of the population working in agriculture can be protected and they will be able to lead a quality life.

Keywords: Health Hazards; Farm Workers; Crop Protection
\end{abstract}

\section{Introduction}

Crop protection is important for managing of weeds, pests and diseases that damage the crops or affect the productivity of farm produce. Proper care of crops has a significant role is in producing higher quality crops with minimal wastage. The main classes of crop protection chemicals are herbicides, insecticides and fungicides. These are being used at every stage of cultivation viz. land preparation, seed treatment, controlling diseases and pests, removal of weeds and at the time of storing grains. Their use is of special concern because of high intrinsic toxicity which may cause harm to human health because of their direct application to crops.

Exposure to pesticides and other agrochemicals at farm constitutes one of the principal occupational risks posing many acute and chronic health problems. The pesticides production amounted to 217 thousand metric tons across India in the year 2019 as compared to 186 metric tons in the year 2015. Several cases of poisoning and deaths occur annually worldwide, due to the use of chemical pesticide, with about three-fourths of these occurring in developing countries. The magnitude of health damage caused by agrochemical exposure varies according to the type of crop cultivated, the type of agrochemical used, the mode of application or exposure, the individual susceptibility and the climatic conditions. Chemicals can enter the body through many routes but the most common ways are through skin and by inhaling. Gases used as pesticides or produced by a reaction when pesticides are applied - including hydrogen sulphide, phosgene and chlorine - affect directly, through irritation, the walls of the respiratory tract, bringing asth- matic reactions among people suffering from bronchial hyperactivity. Recently, the probability of certain pesticides as endocrine disrupting chemicals (EDCs) has been identified [4].

India being an agrarian country employees nearly half of its population in agriculture. Pesticides will remain a tool for modern agriculture, so it is important to design strategies that will reduce pesticide impact [3]. The health status of the people working in agriculture needs to be improved and thus require attention. There is lack of data on how many agricultural workers are adversely affected during crop protection activities and there are no effective ways to find the exact rates of accidents and diseases confronted by them as a result of chemicals used. Also current ergonomic researches and its application in developing countries are mainly focusing on the industrial sector. Inclusion of ergonomic principles for performing the work, improving work place and environment may alleviate the health problems [8]. Thus, there is an urgent need to educate the farm workers to adopt safe methods of work in crop protection through special training programmes and interventions to avoid or minimize hazards.

\section{Methodology}

A sample of 120 agricultural workers engaged in crop cultivation since 8-10 years were selected randomly. The ratio of men and women was equal and thus a total of 60 male and 60 female respondents participated in the present study. A survey was conducted to find the occupational health hazards among agricultural workers during crop protection work i.e. while handling, storing and mak- 
ing use of chemicals and pesticides. The factors causing hazards were also elicited to know the level of knowledge of the respondents towards health and safety in use of different chemicals.

\section{Results and Discussions}

Health hazards in crop protection activities

Exposure to pesticides usually occurs while preparing the spray solutions, filling the sprayers or while applying the pesticide. Prolonged exposure may result in chronic diseases. The health hazards in crop protection studied were categorized under physiological, mechanical, chemical and environmental hazards.

- Physiological hazards: The common physiological hazards elicited were body pain, fatigue, sprains, ligament pull, headache, fever due to overexertion etc. Physiological hazards result usually from long hours of hard work, continuous movement, lifting heavy loads, overexertion, continuous and forceful motions, bending and awkward postures adopted while working. The data indicates that the major physiological hazards reported by male and female respondents during plant protection activities which occurred while spraying or dusting chemicals in the field were fatigue reported by approximately 60 per cent and body pain by 63 per cent of male respondents respectively. This was because a considerable amount of force is required by the worker with repetitive motion of hand while moving continuously in the field. Other hazards reported by male respondents were sprain/ligament pull (33.3\%), headache (41.7\%), excessive sweating (33.3\%) and fever (23.3\%). The physiological hazards were reported by less number of female respondents as they were not quite involved in spraying activities but approximately one-fourth of them reported headache as one of the major physiological hazard while helping their counterparts during work.

- Mechanical hazards: Farm equipment and tools were the common sources of injury, cuts, falls etc. and categorized as mechanical hazards. One - third of the male agricultural workers reported mechanical hazards while handling sprayers. Carelessness during filling the sprayers, cleaning them and using them caused injury to the worker. Using damaged and corrosive equipment and tools also led to cuts while handling and using the equipment and was reported by some of the males and females.

- Chemical hazards: Chemical hazards such as allergic dermatitis or eczema are the most common occupational dermatological infection in agriculture and are caused by the action of solvents and other products present in pesticides used for plant protection. The data illustrated that approximately 53 per cent of males and 23 per cent of females reported skin problem such as burning, inflammation and irritation of skin while handling chemicals. Most of the respondents also reported that the skin of hand gets dry and rough. Eye problems such as watering, irritation, burning sensation and redness of eyes were reported by approximately 42 per cent of male respondents whereas only 15 per cent of female agricultural workers reported this hazard. Approximately one third of males reported the problem of giddiness when the chemicals were inhaled accidentally or if the smell was very pungent, while only 10 per cent of females reported this hazard. It can be concluded that as women were less involved in the tasks when chemicals were used and they were less influenced directly, though indirectly they were also exposed to these hazards while working in fields.

- Environmental hazards: The use of chemicals brought environmental hazards due to the drift of chemicals in air, which a person may inhale without proper protection. Approximately 58 per cent of male farm workers were affected when spraying chemicals in fields and had the problem related to respiration, irritation in respiratory tract and chest tightness and because women accompanied in the plant protection activity or performed other farming activities in the same field approximately 21 per cent also reported respiratory problems. Pesticide drift is also a permanent hazard in pesticide use, because it exists even in the most careful applications, and therefore, can increase the possibility of detrimental effects of pesticide use on the users and the environment [2].

- The Mean Percent Score (MPS) of the respondents for each type of hazard during crop protection indicates that men performing the activities of crop protection were more affected as compared to women. Approximately 60 per cent of males reported environmental hazards, 50 per cent physiological hazards, 43 per cent chemical hazards and one-third mechanical hazards whereas the females reporting all types of hazards ranged between 10-20 per cent.

\section{Factors of hazards in crop protection activities}

- Duration of exposure: The male respondents reported that they have been exposed to farm chemicals between 10 to 25 years with an average exposure duration of 15.6 years. Approximately 60 per cent of the male respondents and 25 per cent of female respondents admitted that they had confronted an accident due to unsafe use of chemical once in their life. The pesticide exposure level also depends on the type of spraying equipment used by the person. Hand spraying with wide-area spray nozzles is usually related to greater exposure than narrow spray nozzles.

- Not using Personal Protective Equipment: Approximately 75 per cent of the male respondents reported that they were not using gloves, masks, protective clothes, appropriate footwear, head gear etc. during performing activities related to crop protection although they were aware of these. The reason for not using was the high cost of PPE and during the hot and humid weather conditions they disliked using it. The protective ability of any PPE depends on its proper use during work and the farmers who rolled the sleeves or took off the gloves in the middle of pesticide handling face increased risk of dermal [7].

- Improper work methods: Approximately 80 per cent of farmers admitted that they did not read the instructions given 
for use. For mixing the chemicals with water they poured it directly into the spraying can and then mixed the pesticides in the can. 30 per cent of the respondents mixed or diluted chemicals with bare hands or with help of a stick without covering their nose and eyes. Use of gloves was made by only by 8-10 per cent of the respondents, while a few of them (5\%) used old cotton cloths as masks. The condition of the sprayers were also not good and 40 per cent of them reported that there were leakages or the nozzle was not working properly. Dermal absorption may occur as a result of splashes and spills when handling (mixing, loading or disposing of) pesticides. To a minor degree, dermal absorption may occur from exposure to great load of residues. The degree of hazard by dermal absorption depends on the toxicity of the pesticide to the skin, the duration of the exposure, the pesticide formulation, and the body part contaminated [1].

- Personal habits and Ignorance of the respondents: Personal hygiene was not observed by the respondents during and after using chemicals. While spraying approximately 45 per cent of male farmers' chewed tobacco or smoked. After handling chemicals 90 per cent of them did not washed their hands with soap, only water was used for washing hands. The chemical contaminated clothes were not changed by maximum of the respondents before eating or sleeping.

- Immediate working in farm: Approximately 25 per cent of the male respondents and 45 per cent of female respondents reported that they continued other farming activities during or soon after the pesticides were sprayed in the fields. The farm women engaged in weeding activities were affected by the chemicals sprayed in the fields for crop protection as they uprooted the weeds usually with their hand which affected the skin [6].

- Storage of chemicals and disposal of empty containers: The chemicals were usually stored or kept in the home by 60 per cent of the respondents and 42 per cent were not aware of the degree of hazardous as they never read the instructions or noticed the signs given on the packaging. 26.5 per cent of the farmers were able to read the labels, understand it and follow the instructions for use correctly. The containers were used at home for other purposes which was reported by 17 per cent of the respondents. Approximately 68 per cent agreed that they were not safely disposing the empty containers or packets of chemicals. Jallow., et al. (2017) found a significant association $(\chi 2=8.98, p<0.05)$ between years of farming experience and safe pesticide storage and disposal [5].

\section{Conclusion}

The crop protection activity brings hazards to the workers and if timely precautions are not taken the health of the largest workforce of the country will be affected. To conclude the top ranking hazards, it can be said that skin problems ranked first followed by body pain and fatigue while spraying or dusting chemicals. Unsafe handling and unsafe methods adopted while use of chemicals led to hazards in most cases. There is a tremendous need for identifica- tion and prevention of hazards to minimise the negative impact on the health and productivity of workers. Ergonomic hazards during work can be minimized or in some tasks entirely prevented with the appropriate interventions. These may include design of equipment, improved work processes and increased awareness of risk factors. Thus, suitable interventions will help in reducing the incidence of hazards thereby reduction in total cost of work, an increase in productivity, and improvement in farmers' quality of life.

\section{Bibliography}

1. Baldi I., et al. "Pesticide contamination of workers in vineyards in France". Journal of Exposure Science and Environmental Epidemiology 16 (2006): 115-124.

2. Damalas CA. "Pesticide drift: Seeking reliable environmental indicators of exposure assessment”. In: Armon R., Hänninen O., editors. Environmental Indicators. Springer; Dordrecht, Netherlands (2015): 251-261.

3. Ekstrom G and Ekbom B. "Pest control in agro-ecosystems: An ecological approach". Critical Review Plant Science 30 (2011): 74-94.

4. Ewence A., et al. "An approach to the identification and regulation of endocrine disrupting pesticides". Food and Chemical Toxicology 78 (2015): 214-220.

5. Jallow Mustapha FA., et al. "Pesticide Knowledge and Safety Practices among Farm Workers in Kuwait: Results of a Survey". International Journal of Environmental Research and Public Health 14.4 (2017): 340.

6. Singh S., et al. "Ergonomic assessment of manual weeding activities in rural areas of Rajasthan in India". Proceedings of International Congress on Humanizing Work and Work environment held at IIT, Mumbai (2011): 11-14.

7. Vitali M., et al. "Operative modalities and exposure to pesticides during open field treatments among a group of agricultural subcontractors". Archives of Environmental Contamination and Toxicology 57 (2009): 193-202.

8. Vyas Rekha and Singh Suman. "Mitigating occupational health hazards of agriculture workers through educational intervention". Indian Journal of Training and Development 38.3 (2008): 21-28.

\section{Assets from publication with us}

- Prompt Acknowledgement after receiving the article

- Thorough Double blinded peer review

- Rapid Publication

- Issue of Publication Certificate

- High visibility of your Published work

Website: www.actascientific.com/

Submit Article: www.actascientific.com/submission.php Email us: editor@actascientific.com

Contact us: +919182824667 